\title{
Políticas educacionais em tempos de golpe: retrocessos e formas de resistência ${ }^{1}$
}

\author{
Educational policies in times of coup: setbacks and forms of resistance
}

\section{Políticas educativas en tiempos de golpe: reveses y formas de resistência}

\author{
Dermeual Saviani ${ }^{2}$ \\ Universidade Estadual de Campinas, Faculdade de Educação, Departamento de Filosofia e \\ História da Educação, Professor titular. \\ https://orcid.org/0000-0002-3148-3055
}

Resumo: Este artigo aborda a política educacional brasileira atual começando por caracterizar a tendência geral de precarização da educação no País expressa na filantropia, na protelação, na fragmentação e na improvisação. Em seguida mostra que os avanços conseguidos pela mobilização dos educadores entre 2003 e 2014 foram interrompidos pelo golpe jurídico-midiático-parlamentar consumado em 31 de agosto de 2016 com o impedimento da então Presidenta da República Dilma Rousseff. Decorreu daí um grande retrocesso expresso na Emenda 95, que congelou os investimentos em educação, inviabilizando as metas do PNE aprovado em junho de 2014, na reforma do ensino médio e no projeto autodenominado "escola sem partido". À guisa de conclusão, são indicadas formas de resistência ao retrocesso que vem se ampliando e aprofundando com a posse do novo governo em $1^{\circ}$ de janeiro de 2019.

Palavras-chave: Educação brasileira. Politica educacional. Reformas do ensino. Retrocesso na educação.

Abstract: This article discusses the current Brazilian educational policy starting by characterizing the general tendency of precarious education in the country expressed in philanthropy, delay, fragmentation and improvisation. It then shows that the progress made by the mobilization of educators between 2003 and 2014 was halted by the legal-media-parliamentary coup consummated on August 31, 2016 with the impediment of then-President Dilma Rousseff. This resulted in a major setback expressed in the reform of high school, in the self-styled project "school without party" and in Amendment 95 that froze investments in education, making impossible the PNE goals approved in June 2014. By way of

Conferência de Abertura do evento com o mesmo título na UFPB. João Pessoa, 7 de novembro de 2017.

Doutor em Filosofia da Educação pela Pontifícia Universidade Católica de São Paulo; Graduado em Filosofia pela Pontifícia Universidade Católica de São Paulo. 
conclusion, some forms of resistance to the backwardness that have been widening and deepening with the inauguration of the new government on January 1, 2019 are indicated.

Keywords: Brazilian education. Educational politics. Educational reform. Setback in education.

Resumen: Este artículo analiza la politica educativa brasileña actual, comenzando por caracterizar la tendencia general depreciación de la educación en el país expresada en filantropía, retraso, fragmentación e improvisación. Luego muestra que el progreso logrado por la movilización de educadores entre 2003 y 2014 se detuvo por el golpe legal, mediático y parlamentario consumado el 31 de agosto de 2016, con el impedimento de la entonces presidente Dilma Rousseff. Esto dio lugar a un grande retroceso expresado en la reforma de la escuela secundaria, el proyecto autodenominado "escuela sin partido" y en la Enmienda 95 que congeló las inversiones en educación, lo que hizo que las metas del PNE aprobadas en junio de 2014, fueran imposibles. A modo de conclusión, se indican algunas formas de resistencia al retroceso que se ha ido ampliando y profundizando con la inauguración del nuevo gobierno el 1 de enero de 2019.

Palabras clave: Educación brasileña. Politica educativa. Reformas educativas. Revés en la educación.

Recebido em 20 de agosto de 2019

Aceito em 25 de novembro 2019

Publicado em 03 de junho de 2020

\section{INTRODUÇÃO: A POLÍTICA EDUCACIONAL BRASILEIRA ANTES DO GOLPE}

Resumidamente, podemos dizer que a política educacional brasileira desde o final da Ditadura (1985) até os dias de hoje se apresenta com características condensadas nas seguintes palavras: filantropia, protelação, fragmentação e improvisação.

A filantropia diz respeito à demissão do Estado em consonância com a ideia do Estado mínimo, o que se traduz na tendência a considerar que a educação é um problema de toda a sociedade e não propriamente do Estado, isto é, dos governos. A impressão é que, em lugar do princípio que figura nas constituições, segundo o qual a educação é direito de todos e dever do Estado, adota-se a diretriz contrária: a educação passa a ser dever de todos e direito do Estado. Com efeito, o Estado se mantém como regulador, como aquele que controla, pela avaliação, a educação, mas transfere para a "sociedade" as responsabilidades pela sua manutenção e pela garantia de sua qualidade. Veja-se como exemplo, no Governo FHC, o mote "Acorda Brasil. Está na hora da escola" (SAVIANI, 1997, p. 11-12) e no Governo Lula, o “Compromisso Todos pela Educação", ementa do decreto que instituiu o PDE. Na divulgação 
da Campanha "Acorda Brasil. Está na hora da escola", o MEC distribuiu um folheto publicitário que continha frases como:

\begin{abstract}
"Os professores precisam ter condições para se atualizar; entre outras coisas, você pode: patrocinar a realização de palestras, seminários e cursos de atualização nas escolas, doar livros e assinaturas de jornais e revistas para uso dos professores. 0 trabalho didático utiliza diferentes materiais: entre outras coisas, você pode: doar máquinas de escrever, videocassetes, projetores, televisores, computadores e impressoras, doar equipamentos de esporte, promover a criação de bibliotecas, ludotecas e videotecas [...]", etc., etc. (SAVIANI, 1997, p. 11).
\end{abstract}

E vai-se nesse diapasão com outras pérolas, chegando a apelar à prestação de "auxílio administrativo à escola" e pedindo para "ajudar as crianças com dificuldade, ministrando aulas de reforço". Fica claro, aí, que o princípio constitucional que define a educação como dever do Estado cede lugar à boa vontade da população num regresso à época em que a educação ainda não era considerada um assunto de responsabilidade pública, permanecendo na alçada da filantropia. Quanto ao "Todos pela Educação", trata-se de um movimento criado pelos empresários, sugerindo que a educação é um problema não restrito ao Estado e aos governos, mas de toda a sociedade, tendo sido encampado pelo Decreto n. 6.094, de 24 de abril de 2007, que originou o Plano de Desenvolvimento da Educação (PDE) ao instituir o Plano de Metas Compromisso Todos pela Educação (SAVIANI, 2009).

A protelação significa o adiamento constante do enfrentamento dos problemas. Tomemos o exemplo dos dois pontos fixados pelo Art. 60 das Disposições Transitórias da Constituição: eliminação do analfabetismo e universalização do ensino fundamental. A constituição fixou o prazo de 10 anos para o cumprimento dessa meta: 1998. 0 Plano Decenal "Educação para Todos”, de 1993, também 10 anos: 2003. 0 FUNDEF, de 1996, igualmente 10 anos: 2006. 0 FUNDEB, de 2007, 14 anos: 2021. 0 PDE, de 2007, 15 anos: 2022. E o PNE, 10 anos, 2024. E assim o Brasil vai avançando pelo século XXI adiando a solução desse problema que os principais países resolveram entre a segunda metade do século XIX e a primeira metade do século XX.

A fragmentação se constata pelas inúmeras medidas que se sucedem e se justapõem perpetuando a frase do Manifesto dos Pioneiros da Educação Nova de 1932: "todos os nossos esforços, sem unidade de plano e sem espírito de continuidade, não lograram ainda criar um sistema de organização escolar" à altura das necessidades do país (AZEVED0 et al., 1932),

A improvisação se manifesta no fato de que para cada ponto que se levanta como importante busca-se logo aprovar uma emenda constitucional, uma lei, ou baixar um decreto ou portaria sem atentar para sua efetiva necessidade e sua justaposição com outras medidas correlatas ou de efeito equivalente. Veja-se o caso do Ensino Fundamental 
de nove anos. Na verdade, a antecipação do início do Ensino Fundamental para os seis anos de idade era uma reivindicação dos prefeitos, o que se devia ao FUNDEF, que absorvia $60 \%$ dos recursos educacionais de estados e municípios destinados ao Ensino Fundamental. Com isso, os municípios ficavam com apenas $40 \%$ para atender à Educação Infantil, incluindo creches e pré-escolas. Daí a reivindicação dos prefeitos de modo a possibilitar que o então último ano da educação infantil pudesse ser coberto com recursos do FUNDEF. Atendendo a essa reivindicação, foi sancionada, em 6 de fevereiro de 2006, a Lei n. 11.274, estendendo a duração do ensino fundamental para nove anos. Criou-se, assim, uma ambiguidade que gerou certa confusão nas cabeças principalmente dos pais, pois o Ensino Fundamental passou a ter nove anos e oito séries. Ou seja, a primeira série ficou correspondendo ao segundo ano. No entanto, em dezembro de 2006, venceu o prazo do FUNDEF e em seu lugar foi criado o FUNDEB, que passou a abranger toda a educação básica. Portanto, agora, toda a Educação Infantil passou a ser coberta com os recursos do Fundo. Revelou-se, portanto, totalmente desnecessária a confusão criada com a lei dos nove anos. Não bastasse isso, em 11 de novembro de 2009 foi aprovada a Emenda Constitucional n. 59, que tornou obrigatória a educação dos quatro aos 17 anos, abrangendo, portanto, toda a segunda etapa da Educação Infantil correspondente à fase pré-escolar.

0 resultado observável empiricamente é a precarização geral da educação em todo o País visível na rede física, nos equipamentos, nas condições de trabalho e salários dos profissionais da educação, nas teorias pedagógicas de ensino e aprendizagem, nos currículos e na avaliação dos resultados.

Sobre a avaliação, cabe observar que a aferição de resultados se tornou a pedrade-toque de toda a organização educacional, sendo que o modelo de avaliação assumido pelo MEC não decorreu de pesquisa sobre a situação educacional brasileira. Sua inspiração veio dos instrumentos internacionais focados na mensuração de resultados.

Matéria publicada no jornal 0 Estado de São Paulo, na edição de 2 de agosto de 2010, com entrevista concedida por Diane Ravitch (2010a, p. 16), informa que ela foi secretária adjunta de educação entre 1991 e 1993 no Governo George H. W. Bush, sendo, em seguida, indicada pelo então Presidente Bill Clinton para assumir o National Assessment Governing Board, instituto responsável pelos testes federais. Firmou-se, assim, como uma das principais defensoras da reforma do ensino nos Estados Unidos, reforma essa que, baseada em metas, introduziu testes padronizados, responsabilização do professor e práticas corporativas de medição e mérito. No entanto, após 20 anos defendendo esse modelo que inspirou as medidas adotadas no Brasil a partir da década de 1990, Ravitch (2011) concluiu que "em vez de melhorar a educação, o sistema em vigor nos Estados Unidos está formando apenas alunos treinados para fazer uma avaliação." E mostrou de forma contundente as limitações desse modelo numa corajosa autocrítica publicada no livro The death and life of the great american school 
system: how testing and choice are undermining education (RAVITCH, 2010b), publicado no Brasil com o título Vida e morte do grande sistema escolar americano: como os testes padronizados e o modelo de mercado ameaçam a educação (RAVITCH, 2011).

No Brasil, esse modelo de avaliação orientado pela formação de rankings e baseado em provas padronizadas aplicadas uniformemente aos alunos de todo o País por meio da "Provinha Brasil", da "Prova Brasil", do “ENEM", do "ENADE” está, na prática, convertendo todo o "sistema de ensino" numa espécie de grande "cursinho pré-vestibular", pois todos os níveis e modalidades de ensino estão se organizando em função da busca de êxito nas provas, buscando aumentar um pontinho no IDEB. Caminham, portanto, na contramão de todas as teorizações pedagógicas formuladas nos últimos 100 anos para as quais a avaliação pedagogicamente significativa não deve se basear em exames finais e, muito menos, em testes padronizados. Devem, sim, procurar avaliar o processo, considerando as peculiaridades das escolas, dos alunos e dos professores.

Em sintese, eis a perversa equação que expressa o significado da política educacional brasileira desde o final da Ditadura (1985) até os dias de hoje: Filantropia + protelação + fragmentação + improvisação = precarização geral do ensino no País.

\section{A POLÍTICA EDUCACIONAL BRASILEIRA HOJE, EM TEMPOS DE GOLPE: RETROCESSOS}

Mas se a política educacional tem sido marcada pelas limitações que acabei de indicar, o campo dos profissionais da educação vem, desde o final da década de 1970, lutando para superar esses limites com a mobilização da Associação Nacional de Pesquisa e Pós-Graduação em Educação (ANPEd), fundada em 1977; do Centro de Estudos Educação e Sociedade (Cedes), cuja fundação foi articulada em 1978 e formalizada em março de 1979; da Associação Nacional de Educação (Ande), fundada em 1979; da Confederação dos Professores do Brasil (CPB), constituída em 1979 a partir da Confederação dos Professores Primários do Brasil (CPPB), criada em 1960; da Confederação Nacional dos Trabalhadores da Educação (CNTE), na qual se transformou a CPB em 1989; da Associação Nacional dos Docentes do Ensino Superior (ANDES), criada em 1981; além da Federação das Associações de Servidores das Universidades Públicas (Fasubra), criada em 1978.

Como expressão dessa mobilização os educadores formularam um projeto da Lei de Diretrizes e Bases da Educação Nacional que, antecipando-se ao governo, foi protocolado na Câmara dos Deputados sob o número 1.158-A/88 em dezembro de 1988, embora, ao final, tenha sido derrotado pela interferência do Governo FHC no Senado. lgualmente, após a aprovação 
da LDB, os profissionais da educação, reunidos no I e || Congressos Nacionais de Educação (Coned), realizados respectivamente em agosto e novembro de 1997, ambos em Belo Horizonte, elaboraram o projeto de Plano Nacional de Educação (PNE) conhecido como "projeto da sociedade brasileira", que também se antecipou ao governo dando entrada na Câmara dos Deputados em 10 de fevereiro de 1998, sendo seguido, dois dias depois, do projeto do MEC que, embora apensado ao anterior, teve a prioridade invertida porque o governo tinha maioria no congresso e reverteu a iniciativa dos educadores. Enfim, de modo especial a partir do segundo mandato de Lula, o protagonismo dos educadores tornou-se mais efetivo, logrando vários avanços e convergindo para a l e II Conferências Nacionais de Educação (Conae), tendo como tema central a construção do Sistema Nacional de Educação e do novo Plano Nacional de Educação. E quando se alimentou a expectativa de algum avanço mais significativo com a aprovação do novo PNE e com a destinação de parcela considerável dos recursos do pré-sal para a educação, sobreveio - golpe e estamos diante de um retrocesso não de anos, mas de décadas.

Tal retrocesso incide sobre vários aspectos, a começar pelo Plano Nacional de Educação (PNE), aprovado pela Lei n. 13.005, sancionada em 25 de junho de 2014, uma vez que as medidas pós-golpe já o tornaram letra morta, pois várias de suas metas já venceram sem serem atingidas, e as que ainda não venceram não têm mais a mínima chance de se viabilizar. Vejamos: a) metas já vencidas: Meta 1 (Educação Infantil) - universalizar, até 2016, a Educação Infantil na pré-escola para as crianças de quatro a cinco anos de idade; Meta 3 (Ensino Médio) - universalizar, até 2016, o atendimento escolar para toda a população de 15 a 17 anos de idade; Meta 18 - assegurar, no prazo de dois anos (portanto, até 2016), a existência de planos de carreira para os profissionais de todos os sistemas de ensino; Meta 19 - assegurar condições, no prazo de dois anos (portanto, também até 2016), para a efetivação da gestão democrática; b) metas a vencer: Meta 2 - universalizar o Ensino Fundamental de nove anos para toda a população de seis a 14 anos até o último ano de vigência deste PNE (2024); Meta 4 - universalizar, para a população de quatro a 17 anos com deficiência, transtornos globais do desenvolvimento e altas habilidades ou superdotação, atendimento educacional especializado. Essa meta trata, portanto, da educação especial, e como não menciona a data, considera-se o final da vigência do Plano, ou seja, 2024, como prazo para ser atingida; Meta 20 - ampliar o investimento público em educação pública de forma a atingir, no mínimo, o patamar de 7\% do PIB no quinto ano de vigência desta Lei (2019) e, no mínimo, o equivalente a 10\% do PIB ao final do decênio (2024). Vê-se que a parte da Meta 20, que estabeleceu o prazo de cinco anos para se chegar ao índice de $7 \%$ do $\mathrm{PIB}$ destinado à educação pública, já venceu no último dia 25 de junho. E com a Emenda Constitucional apelidada de PEC do fim do mundo, que impede o aumento dos gastos públicos por 20 anos, todas as metas do PNE já estão inviabilizadas pelo menos até 2037.

Mas essa inviabilização das metas do PNE é apenas um dos aspectos pelos quais as reformas regressivas do Governo Temer, que vêm tendo sequência no atual governo, procuram neutralizar os limitados avanços dos Governos Lula e Dilma, retomando o espírito 
autoritário que foi a marca do período da Ditadura Militar. Esse autoritarismo fica evidente na reforma do Ensino Médio, baixada por medida provisória sem sequer dar conhecimento prévio às Secretarias de Educação e aos Conselhos Estaduais de Educação que, pela LDB, são os responsáveis pela oferta pública desse nível de ensino. Como responsáveis pelo Ensino Médio, os estados e o Distrito Federal deveriam ser consultados sobre a proposta de reforma desse nível de ensino. No entanto, nem mesmo foram informados, sendo surpreendidos com a entrada em vigor da referida reforma, uma vez que, sendo baixada por medida provisória, passou a valer imediatamente após sua promulgação. 0 caráter autoritário fica claro, também, nas medidas relativas à realização da III Conferência Nacional de Educação intervindo no Fórum Nacional de Educação à revelia do que dispõe a Lei n. 13.005, de 25 de junho de 2014 , que aprovou o Plano Nacional de Educação 2014-2024. Com essa intervenção arbitrária o governo mudou a composição do Fórum sem consulta às entidades que, conforme as normas legais, nele tinham assento. Tal autoritarismo se faz presente, ainda, no movimento "escola sem partido", merecidamente chamado por seus críticos de "lei da mordaça", pois explicita uma série de restrições ao exercício docente, negando o princípio da autonomia didática consagrado nas normas de funcionamento do ensino.

Mas como justificar o recurso à medida provisória na reforma do Ensino Médio? $\mathrm{Na}$ verdade, o estatuto jurídico da medida provisória é equivalente ao do Decreto-Lei, instrumento de que, normalmente, lançam mão os regimes ditatoriais nos quais o Executivo enfeixa em si as prerrogativas do Poder Legislativo. Nesse sentido, esse dispositivo da Constituição de 1988 (Art. 62, modificado pela Emenda n. 32, de 11 de setembro de 2001) tem como antecedentes o Decreto-Lei das Constituições de 1937, da ditadura do Estado Novo e de 1967 com a Emenda n. 1, de 1969, da ditadura militar e, como inspiração mais direta, o provvedimento provvisorio italiano, disciplinado no art. 77 da Constituição de 1947, usualmente conhecido por "decreto-legge". Mas há uma nítida diferença entre o provvedimento provvisorio italiano e a medida provisória brasileira, que fica clara na resposta a uma pergunta que teria sido feita pelo próprio Michel Temer quando era apenas vice-presidente: o que acontece se a medida provisória não for aprovada pelo Parlamento Italiano? Resposta curta e grossa: “0 Gabinete cai”, pois o modelo político italiano é diferente do brasileiro, que não responsabiliza politicamente o Presidente da República no caso de não aprovação da medida provisória. Por isso, embora a Constituição estabeleça que a edição de medida provisória deva ocorrer apenas "em caso de relevância e urgência", o Presidente da República tem abusado do dispositivo da medida provisória, adotando-o indiscriminadamente de acordo com seu exclusivo alvedrio, cioso de que não arcará com consequência alguma no caso de não aprovação pelo Poder Legislativo. Assim é que na situação atual de um governo ilegítimo, a medida provisória se converte num recurso para o exercício de um poder autoritário. É nessa circunstância que a Reforma do Ensino Médio foi baixada pela Medida Provisória n. 746, de 22 de setembro de 2016.

A referida Medida Provisória registra como ementa: 
Institui a Politica de Fomento à Implementação de Escolas de Ensino Médio em Tempo Integral, altera a Lei $n^{\circ}$ 9.394, de 20 de dezembro de 1996, que estabelece as diretrizes e bases da educação nacional, e a Lei $n^{\circ} 11.494$ de 20 de junho 2007, que regulamenta o Fundo de Manutenção e Desenvolvimento da Educação Básica e de Valorização dos Profissionais da Educação, e dá outras providências. (CÂMARA DOS DEPUTADOS, 2016).

De fato, a reforma altera diversos artigos da LDB e institui novas regras que não cabe aqui detalhar, importando destacar apenas dois aspectos: a pretensão de instituir escolas de Ensino Médio em tempo integral e a organização do Ensino Médio em cinco itinerários formativos previstos no Art. 36: I - Linguagens; || - Matemática; || - Ciências da natureza; IV - Ciências humanas; e V - Formação técnica e profissional.

Assim que foi promulgada, a medida provisória foi alvo de uma avalanche de críticas, entre as quais destaco as seguintes:

0 Fórum Nacional de Educação emitiu, no mesmo dia 22 de setembro de 2016, sua $45^{a}$ Nota Pública na qual, entre outras considerações, afirma:

\footnotetext{
0 governo Temer erra no método e no processo, restritivos e impeditivos do debate e do encaminhamento adequado sobre a matéria nas redes e sistemas de educação e, também, erra no conteúdo e suas repercussões no pais, o que gerará mais atrasos e retrocessos em face da necessária formulação e implementação de medidas consistentes e bem fundamentadas para o Ensino Médio. (FÓRUM NACIONAL DE EDUCAÇÃO, 2016).
}

E registra 23 pontos negativos, entre os quais destaco os seguintes, mantendo os negritos que constam na Nota Pública do Fórum:

b. não trata de questões basilares, como as condições objetivas e infraestruturais das escolas, a profissionalização e valorização dos profissionais da educação, a relação discente-turma-docente, a inovação nas/das práticas pedagógicas, entre outros aspectos;

c. empobrece a formação para reduzir custos e precarizar o trabalho docente, desconhecendo que para a oferta de qualquer modelo formativo é necessário enfrentar o déficit de docentes em muitas áreas;

f. torna o inglês obrigatório sem ocupar-se das objetivas e distintas realidades das redes e sistemas, abrindo enorme flanco para sua oferta por "grupos e empresas interessadas" junto a redes e sistemas fragilizados e compelidos a cumprir uma obrigação; 
l. possibilita a ampliação da presença do "setor produtivo" no campo da formação técnica e profissional;

m. abre enorme espaço para a pressão local de grupos interessados sobre os sistemas ao tratar das possibilidades de cumprimento de exigências curriculares do Ensino Médio, "mediante regulamentação própria" dos sistemas;

n. vilipendia a formação docente e desmonta a meta 15 constante da Lei $n^{\circ}$ 13.005/14, do Plano Nacional de Educação, ao cristalizar a atuação de "profissionais com notório saber reconhecido pelos respectivos sistemas de ensino para ministrar conteúdos de áreas afins à sua formação", sem estabelecer qualquer diálogo com conselhos de educação e instituições formadoras;

p. propõe à comunidade educacional "um salto no escuro" ao sugerir a necessária substituição de disciplinas por "itinerários formativos" ancorados em uma Base Nacional Comum ainda não concluída e em uma articulação com o mercado de trabalho, alicerçados na reedição da dualidade e fragmentação entre a educação que será oferecida aos jovens das elites (formação intelectual) e aos jovens trabalhadores e filhos e filhas de trabalhadores (formação manual), reeditando o modelo do período ditatorial, marcado pelo viés eficienticista e mercadológico;

q. propõe uma "Política de Fomento à Implementação de Escolas de Ensino Médio em Tempo Integral" que, no contexto das medidas regressivas de ajuste fiscal e restrição do gasto público em educação, a exemplo da PEC 241/16, representará, na prática, uma medida para atrair e ludibriar redes e sistemas de educação que, malgrado, serão deixados à própria sorte em curto espaço de tempo;

r. estabelece que o acesso ao apoio financeiro para implementação do modelo será viabilizado àqueles que "atendam às condições previstas em ato do Ministro de Educação", mais uma vez ignorando o diálogo por meio da instância permanente de negociação e cooperação federativa;

s. estabelece que "transferência de recursos será realizada anualmente, a partir de valor único por aluno, respeitada a disponibilidade orçamentária para atendimento, a ser definida por ato do Ministro de Estado da Educação" ignorando, mais uma vez, a instância permanente de negociação e cooperação federativa e, particularmente, desconhecendo a legislação (PNE) e toda a discussão sobre o Custo Aluno Qualidade (CAQ) e Custo Aluno Qualidade inicial (CAQi) e as diversidades regionais;

v. silencia em relação à forma como se garantirá o direito de acesso à Educação Básica para mais de dois milhões de jovens de 15 a 17 anos que estudam e trabalham ou só trabalham; 
Além do Fórum, também os Conselhos Estaduais de Educação se manifestaram.

0 Conselho Estadual de Educação do Rio Grande do Sul (CEE/RS) emitiu sua manifestação em 28 de setembro de 2016. A partir de quatro considerandos, em que mostra o caráter arbitrário e autoritário da Medida Provisória, o CEE/RS defende a sua retirada para que a reforma seja precedida de um debate amplo com as escolas e com os profissionais da educação em consonância com o Pacto Nacional do Ensino Médio e com o disposto no Plano Nacional de Educação.

0 Conselho Estadual de Educação do Paraná (CEE/PR), reunido em sessão plenária na data de 21 de outubro de 2016, registra oito pontos, sendo que os quatro últimos se referem diretamente à situação dramática vivida pela rede pública do estado com um grande número de escolas ocupadas pelos estudantes.

Para efeitos desta minha exposição, destaco o ponto de número 4:

4. Ainda como evidência dessa incompreensivel forma de encaminhar a discussão de políticas públicas, ressaltamos que sequer os Sistemas Estaduais de Educação foram consultados ou mesmo informados previamente dessa proposta, alijando-se, assim, do debate aqueles que devem ser os principais organismos reguladores e executores das medidas nela delineadas. (PARANÁ, 2016).

0 Conselho Estadual de Educação da Bahia (CEE/BA) emitiu Nota Pública em 03 de outubro de 2016 externando sua contrariedade para com a Medida Provisória, centrando-se em duas premissas fundamentais:

a) DO MÉTODO - refere-se à ausência de discussão com a sociedade, configurando, pelo expediente da Medida Provisória, a intervenção do poder executivo federal na educação nacional, enfraquecendo o papel do Conselho Nacional e, consequentemente, dos Conselhos Estaduais e Municipais de Educação;

b) DO CONTEÚDO, posicionando-se contra o empobrecimento curricular preconizado pela reforma.

A essas manifestações aduzo algumas considerações finais levando em conta o núcleo da reforma que se condensa no caput do Art. 36 que, para maior clareza, reproduzo a seguir:

\footnotetext{
Art. 36. 0 currículo do ensino médio será composto pela Base Nacional Comum Curricular e por itinerários formativos específicos, a serem definidos pelos sistemas de ensino, com ênfase nas seguintes áreas de conhecimento ou de atuação profissional:
} 


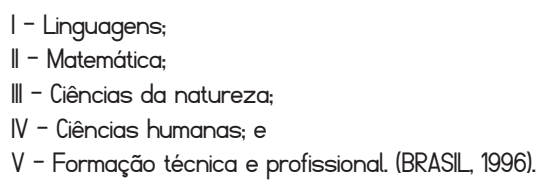

E condenso meus comentários nas seguintes indagações:

a) Flexibilidade ou predeterminação camuflada dos itinerários?

De fato, em lugar da apregoada flexibilidade promove-se uma predeterminação camuflada dos itinerários, o que significa que, na prática, a grande maioria dos alunos será encaminhada para o quinto itinerário, "formação técnica e profissional".

b) Liberdade de escolha dos adolescentes ou descarte da responsabilidade dos adultos?

Argumentando com o princípio da flexibilidade, que permitiria aos alunos a livre opção pelo itinerário que correspondesse aos respectivos projetos de vida, comete-se uma falácia, pois como esperar que adolescentes na faixa de 15 anos já estejam em condições de definir seu projeto de vida e exercer sua liberdade de escolha elegendo um itinerário consentâneo com seu projeto de vida? Ora, nós sabemos que mesmo os jovens já na faixa dos 18 a 20 anos têm dificuldade de escolher a carreira a seguir e, por isso, é frequente que iniciem um curso superior e, ao final do primeiro ano, abandonem o curso para prestar novo vestibular para outro curso. Em lugar da liberdade de escolha dos alunos, o que a reforma promove é a demissão da responsabilidade dos adultos, de modo geral, e, especificamente, dos professores quanto à orientação que lhes cabe propiciar a estudantes ainda na idade da adolescência.

c) Ensino em período integral para todos ou exclusão integral de todos os que trabalham?

Em lugar de ensino em tempo integral para todos ocorreria, se fosse generalizado o tempo integral, a exclusão de todos os que trabalham, pois não poderiam compatibilizar o horário de trabalho com a frequência às aulas. Na fase de redemocratização após a Ditadura Militar, o que se procurou fazer foi o contrário, ou seja, determinou-se que as universidades públicas oferecessem vagas no período noturno exatamente para permitir que os jovens que necessitam trabalhar pudessem frequentar as aulas nessas universidades. Assim é que a Constituição do Estado de São Paulo determinou, no § único do Art. 253, que "as universidades públicas estaduais deverão manter cursos noturnos que, no conjunto de suas unidades, correspondam a um terço pelo menos do total das vagas por elas oferecidas." (SÃO PAUL0, 1989). 
d) Educação integral para todos ou uma vitrine para efeito demonstração reduzido a pequenos grupos elitizados?

Efetivamente, em lugar de educação integral para todos, apenas se promove uma vitrine para efeito demonstração reduzido a pequenos grupos, uma vez que, ao regulamentar o Programa de Fomento à Implementação de Escolas de Ensino Médio em Tempo Integral, o MEC limitou a no máximo 30 escolas por estado. Ora, trata-se de um número extremamente reduzido quando se considera, por exemplo, que o Rio Grande do Sul tinha 1.200 escolas estaduais de nível médio, em 2016, e o Estado de São Paulo, em 2003, já tinha 3.242 escolas.

No entanto, o governo, em lugar de levar em conta a avalanche de críticas que obrigaria a uma revisão, senão a uma reversão da orientação impressa à reforma, vem adotando a postura contrária. Ignora as críticas e lança uma agressiva campanha publicitária com muitas inserções diárias nos meios de comunicação tentando iludir a população ao passar a ideia de que se trata de uma reforma baseada em amplo diálogo e que conta com o apoio de 72\% dos estudantes do Ensino Médio. E chega, inclusive, ao desplante de colocar no ar uma propaganda com um indivíduo que afirma que sua vida mudou quando passou a cursar uma escola de tempo integral, o que the permitiu entrar na faculdade, obter uma bolsa para se formar engenheiro na Espanha e agora é um profissional reconhecido na Espanha. Ora, então essa é uma propaganda do Governo do PT, pois essa pessoa cursou a escola de tempo integral bem antes dessa reforma do Ensino Médio e, além disso, teria se beneficiado do Programa Ciência sem Fronteira para obter a bolsa e estudar na Espanha. Mas a população, de modo geral, não faz essa ilação e acaba sendo induzida a acreditar que esse governo a está favorecendo.

Enfim, para concluir essa incursão sobre os retrocessos provocados pelo golpe na educação, abordo o problema da "escola sem partido" que surgiu no âmbito da sociedade civil, constituiu-se como uma ONG e agora se apresenta na forma de projetos de lei na Câmara dos Deputados, no Senado Federal e em várias Assembleias Estaduais e Câmaras Municipais do País. A motivação dessa ofensiva da direita com a consequente investida sobre a educação tem um duplo componente.

0 primeiro é de caráter global e tem a ver com a fase atual do capitalismo que, tendo tomado conta de todo o globo, já não tem mais como se expandir; e, esgotando todas as suas possibilidades, entrou em profunda crise de caráter estrutural. Nessas circunstâncias a classe dominante já não consegue mais ser dirigente, ou seja, vai perdendo sua capacidade hegemônica, não conseguindo obter o consenso das demais classes em torno da legitimidade de seu domínio. Ocorre, então, o acirramento da luta de classes. Não podendo se impor racionalmente, a classe dominante precisa recorrer a mecanismos de coerção no plano da sociedade política combinados com iniciativas no plano da sociedade civil que envolvem, por um lado, o uso maciço dos meios de comunicação promovendo uma verdadeira lavagem cerebral 
junto à população, e, por outro lado, a investida no campo da educação escolar tratada como mercadoria e transformada em instrumento de doutrinação. Essa é a tendência que vem se intensificando em todos os países com a adoção de políticas regressivas classificadas pelos analistas como neoliberais e com concepções irracionalistas, no plano cultural, subsumidas sob a denominação de pós-modernas.

0 segundo componente tem a ver com a especificidade da formação social brasileira marcada pela resistência de sua classe dominante em incorporar os de baixo, no dizer de Florestan Fernandes, ou as classes subalternas, na expressão gramsciana, na vida política, tramando golpes sempre que pressente o risco da participação das massas nas decisões políticas. Daí o caráter espúrio de nossa democracia alternando a forma restrita, quando o jogo democrático é formalmente assegurado, com a forma excludente em que a denominação "democracia" aparece como eufemismo de ditadura. É essa classe dominante que agora, no contexto da crise estrutural do capitalismo, dá vazão ao seu ódio de classe mobilizando uma direita raivosa que se manifesta nos meios de comunicação convencionais, nas redes sociais e nas ruas. Nesse contexto, se aprovado o projeto da escola sem partido, todo o ensino, incluída a formação dos professores, estará atrelado a esse processo de destituição da democracia como regime baseado na soberania popular, colocando o País à mercê dos interesses do grande capital e das finanças internacionais. Importa, então, enfrentar teórica e praticamente toda essa mobilização que tem como carro-chefe, a "escola sem partido". Do ponto de vista teórico, contamos com uma concepção pedagógica cujo entendimento das relações entre educação e política é diametralmente oposta àquela esposada pela autodenominada "escola sem partido". Trata-se da pedagogia histórico-crítica.

Pode-se considerar que o entendimento da pedagogia histórico-crítica sobre as relações entre escola e política é aquele que está sucintamente expresso no capítulo quarto do livro Escola e democracia, denominado Onze teses sobre educação e política (SAVIANI, 2012, p. 81-90). Ali se esclarece que educação e política são práticas distintas, mas inseparáveis entre si. Assim, embora não exista identidade entre educação e política (tese 1), toda prática educativa contém, inevitavelmente, uma dimensão política (tese 2), assim como toda prática política contém, inevitavelmente, uma dimensão educativa (tese 3).

Só é possível compreender a dimensão política da educação na medida em que se explicita a especificidade da prática educativa (tese 4), do mesmo modo que só é possível compreender a dimensão educativa da política na medida em que se explicita a especificidade da prática política (tese 5). Ora, a especificidade da prática educativa define-se pelo caráter de uma relação que se trava dominantemente entre contrários não antagônicos (tese 6), o que significa que se trata de uma relação de hegemonia alicerçada na persuasão, no consenso, na compreensão. Por sua vez, a especificidade da prática política se define pelo caráter de uma relação que se trava entre contrários antagônicos (tese 7) sendo, pois, uma relação de 
dominação alicerçada em dissuasão, dissenso, repressão. Assim dispostas, as relações entre educação e política dão-se na forma de autonomia relativa e dependência recíproca (tese 8), realizando-se diferentemente conforme as variações históricas de sua manifestação, o que nos permite constatar que as sociedades de classe se caracterizam pelo primado da política, ocorrendo, em consequência, a subordinação real da educação à prática política (tese 9).

Ora, é essa a situação em que nos encontramos, pois a sociedade capitalista é dividida em classes com interesses antagônicos. Essa é a razão do primado da política. Uma vez que a relação política se trava fundamentalmente entre antagônicos, nas sociedades de classes ela se constitui na prática social fundamental. Nessas condições, a dependência da educação em relação à política é maior do que a da política em relação à educação. Daí a subordinação da educação diante da política.

Se as condições de exercício da prática política estão inscritas na essência da sociedade capitalista, as condições de exercício da prática educativa estão inscritas na essência da realidade humana, mas são negadas pela sociedade capitalista, não podendo se realizar aí senão de forma subordinada, secundária. Por aí se pode entender o "realismo" da política e o "idealismo" da educação. De fato, acreditar que estão dadas em nossa sociedade as condições para a realização plena da educação é assumir uma atitude idealista. Inversamente, nesta sociedade é realista quem considera a política como a prática dominante à qual se subordina a educação. Mas se trata de uma subordinação histórica e, como tal, não só pode como deve ser superada. E superada a sociedade de classes, cessa o primado da política e, em consequência, a subordinação da educação (tese 10).

Assim, chegado o momento histórico em que prevalecem os interesses comuns, a dominação cede lugar à hegemonia, a coerção à persuasão, a repressão desfaz-se, prevalecendo a compreensão. Então estarão dadas as condições para o pleno exercício da prática educativa. Sendo uma relação que se trava entre antagônicos, a política supõe a divisão da sociedade em partes inconciliáveis, devendo, necessariamente, ser partidária. Inversamente, a educação, por ser uma relação entre não antagônicos, supõe a união e tende para a universalidade, não podendo, portanto, ser partidária. A prática política se apoia na verdade do poder, enquanto a prática educativa se apoia no poder da verdade. E a verdade, a ciência, não é desinteressada.

No entanto, a classe dominante não se interessa pela verdade, pois isso evidenciaria a dominação que exerce sobre as outras classes. Em contraposição, a classe dominada tem todo interesse que a verdade se manifeste porque isso põe em evidência a exploração a que é submetida, engajando-a na luta de libertação. É esse o sentido da frase "a verdade é sempre revolucionária", o que explica por que a classe efetivamente capaz de exercer a função educativa em cada etapa histórica é aquela que está na vanguarda, a classe historicamente revolucionária. 
Assim, como conclusão necessária das 10 teses que explicitam como se dão historicamente as relações entre política e educação, segue-se que a função política da educação se cumpre na medida em que ela se realiza enquanto prática especificamente pedagógica (tese 11). A importância política da educação reside, enfim, no cumprimento de sua função própria, que consiste na socialização do conhecimento. E, especificamente no caso da escola, sua importância política reside no cumprimento de sua função própria: a socialização do saber elaborado, sistemático, assegurando, às novas gerações, a plena apropriação das objetivações humanas mais ricas representadas pela produção científica, filosófica e artística.

Pelo exposto percebe-se que a posição da pedagogia histórico-crítica se contrapõe radicalmente ao programa da "escola sem partido". Para a pedagogia histórico-crítica na sociedade de classes, portanto, na nossa sociedade, a educação é sempre um ato político, dada a subordinação real da educação à política. Dessa forma, agir como se a educação fosse isenta de influência política é uma forma eficiente de colocá-la a serviço dos interesses dominantes. E é esse o sentido do programa "escola sem partido" que visa subtrair a escola do que seus adeptos entendem como "ideologias de esquerda", colocando-a sob a influência da ideologia e dos partidos da direita, portanto, a serviço dos interesses dominantes. Ao proclamar a neutralidade da educação diante da política, o objetivo a atingir é o de estimular o idealismo dos professores fazendo-os acreditar na autonomia da educação em face da política, o que os fará atingir o resultado inverso ao que estão buscando: em lugar de estar preparando seus alunos para atuar de forma autônoma e crítica na sociedade, estarão formando para ajustálos à ordem existente e aceitar as condições de dominação às quais estão submetidos. Eis por que a "escola sem partido" se origina de partidos situados à direita do espectro poĺtico, com destaque para o Partido Social Cristão (PSC), Partido Social Liberal (PSL) e PSDB, secundados pelo DEM, PP, PR, PRB e os setores mais conservadores do MDB. Como se vê, a "escola sem partido" é a escola dos partidos da direita, os partidos conservadores e reacionários que visam manter o estado de coisas atual com todas as injustiças e desigualdades que caracterizam a forma de sociedade dominante no mundo de hoje.

Enfim, guiados pela pedagogia histórico-crítica, é imperativo organizar na forma da resistência ativa a luta contra as medidas do governo imposto após o golpe e especificamente contra a "escola sem partido" e contra tudo o que ela representa.

A luta contra o projeto de lei deve ser travada mostrando que se trata de uma aberração, pois fere o bom senso, vai na contramão do lugar atribuído à escola na sociedade moderna e nega os princípios e normas vigentes no Brasil, sendo manifestamente anticonstitucional.

Fere o bom senso, pois retira dos professores o papel a eles inerente de formar as novas gerações para se inserir ativamente na sociedade, o que implica trabalhar os 
conhecimentos disponíveis tendo como critério e finalidade a busca da verdade sem qualquer tipo de restrição.

Vai na contramão da sociedade moderna que, no século XVIII, forjou o conceito de escola pública estatal e buscou implantar, no século XIX, os sistemas nacionais de ensino como instrumentos de democratização com a função de converter os súditos em cidadãos. É essa a condição para a existência das sociedades democráticas mesmo sob a forma capitalista e burguesa que proclama a democracia como o regime baseado na soberania popular. E o povo, para se transformar de súditos em cidadãos, isto é, para ser capaz de governar ou de eleger e controlar quem governa, deve ser educado. Para esse fim é que foi instituída a escola pública universal, obrigatória, gratuita e laica.

Em consonância com esse significado histórico da escola, a Constituição vigente no Brasil define como finalidade da educação o "pleno desenvolvimento da pessoa, seu preparo para o exercício da cidadania e sua qualificação para o trabalho." (BRASL, 1988). Ora, o preparo para o exercício da cidadania tem um significado precipuamente político. Mas, mesmo que consigamos que o projeto de lei venha a ser rejeitado, é preciso organizar a luta contra o programa da "escola sem partido", pois, mesmo nesse caso, os adeptos do referido movimento não desistirão de procurar, pelos mais diferentes meios, fazer valer as suas posições. Consequentemente, certa vigilância e pressão sobre os professores acontecerão e não apenas nas escolas particulares, mas também nas públicas, uma vez que a iniciativa privada, por meio de vários organismos, vem crescentemente interferindo na formulação das políticas educacionais e atuando na montagem dos currículos, no conteúdo do ensino por meio de materiais escolares, com destaque para a volta das apostilas, vendendo pacotes para as redes públicas de ensino. Além disso, os adeptos do dito movimento já ocupam postos na rede pública com tendência a ampliar essa participação, visando a fazer prevalecer seus interesses e sua visão do papel da escola. E o risco da vigilância torna-se ainda mais presente, uma vez que já há propostas de instalação de câmeras no interior das salas de aula, o que significa que o princípio da "liberdade de cátedra", ou seja, a autonomia do professor na sala de aula acabará por ser simplesmente abolido.

\section{CONCLUSÃO: FORMAS DE RESISTÊNCIA}

Diante do exposto, fica evidente a necessidade de se organizar um amplo e consistente movimento de resistência contra o governo ilegítimo e antipopular de modo geral e, especificamente, no campo da educação. Cabe, pois, advogar a resistência ativa que implica dois requisitos: a) que seja coletiva, pois as resistências individuais não têm força para se 
contrapor ao poder dominante exercido pelo governo ilegítimo, antipopular e antinacional; b) que seja propositiva, isto é, que seja capaz de apresentar alternativas às medidas do governo e de seus asseclas. Essa forma de resistência é indispensável como estratégia de luta por uma escola pública livre das ingerências privadas balizadas pelos interesses do mercado.

A resistência já se encontra em andamento com as iniciativas da Frente Brasil Popular que, além do Plano Popular de Emergência lançado em 29 de maio de 2017, centrado em 10 eixos (democratização do Estado; política de desenvolvimento, emprego e renda; reforma Agrária e agricultura familiar; reforma Tributária; direitos sociais e trabalhistas; direito à saúde, à educação, à cultura, à moradia; segurança pública; direitos humanos e cidadania; defesa do meio ambiente; e política externa soberana), realizou, no primeiro semestre de 2018, o Congresso do Povo Brasileiro, com o objetivo de "construir com o povo e para o povo um projeto de nação." Cumpre, então, articular a essa mobilização a iniciativa do Fórum Nacional de Educação que, diante dos seguidos constrangimentos criados pelo MEC, decidiu se constituir em entidade autônoma nomeando-se Fórum Nacional Popular de Educação. E, em consequência, nos termos do que foi aprovado pela Lei n. 13.005, de 25 de junho de 2014 , que instituiu o PNE 2014-2024, coordenou as etapas preparatórias que desembocaram na III Conferência Nacional Popular de Educação (Conape), realizada também de forma autônoma, independente e em contraposição ao MEC. Como base para as ações de resistência, proponho como necessária a rearticulação dos Fóruns municipais, estaduais e nacional em defesa da escola pública, mas agora não se limitando aos profissionais da educação e, sim, ampliando-se para abarcar os sindicatos de trabalhadores e movimentos sociais. Estaremos, assim, desencadeando uma grande mobilização de resistência ativa contra o golpe jurídicomidiático-parlamentar que vitimou o país. Devemos nos preparar para uma luta longa, pois não sabemos por quanto tempo as forças políticas que usurparam o poder nele vão se manter. Tudo indica que pretendem permanecer indefinidamente. Aliás, quando do golpe militar também se afirmou que fora feito para salvar a democracia e livrar o País de República Sindicalista, do comunismo; e os militares, restabelecida a ordem, devolveriam o poder aos políticos. Ficaram 21 anos. Agora estamos diante de um verdadeiro "suicídio democrático", ou seja, as próprias instituições ditas democráticas golpeiam o Estado Democrático de Direito pela ação articulada da grande mídia, do parlamento e do judiciário que, pelo golpe, se apossaram do executivo.

Enfim, nessa fase difícil que estamos atravessando, marcada por retrocesso político com o acirramento da luta de classes lançando mão da estratégia dos golpes parlamentares, visando a instalar governos ilegítimos para retomar sem rebuços a agenda neoliberal, resulta imprescindivel combatermos as medidas restritivas dos direitos sociais, entre eles o direito a uma educação de qualidade, pública e gratuita, acessível a toda a população. Essa foi e continua sendo, agora de forma ainda mais incisiva, a nossa luta. A luta de todos os educadores do Brasil. 


\section{REFERÊNCIAS}

AZEVEDO, F. de. et al. 0 manifesto dos pioneiros da educação nova. [S. l.: s. n.], 1932.

BRASIL. Constituição. República Federativa do Brasil de 1988. Brasília, DF: Senado Federal, 5 out. 1988.

BRASIL. Lei n. 9.394, de 20 de dezembro de 2016. Estabelece as diretrizes e bases da educação nacional. Diário Oficial da União, Brasília, DF, 21 dez. 2016.

CÂMARA DOS DEPUTADOS. Medida Provisória n. 746, de 22 de setembro de 2016. Institui a Política de Fomento à Implementação de Escolas de Ensino Médio em Tempo Integral, altera a Lei $n^{\circ} 9.394$, de 20 de dezembro de 1996, [...] e dá outras providências. Diário Oficial da União, Brasília, DF, 23 set. 2016.

FÓRUM NACIONAL DE EDUCAÇÃO. $45^{\circ}$ Nota Pública do Fórum Nacional de Educação - Sobre a Medida Provisória relativa ao ensino médio. Brasília, DF, 22 set. 2016.

PARANÁ. Conselho Estadual de Educação. Comunicado Oficial. Curitiba, 21 out. 2016.

RAVITCH, D. "Nota mais alta não é educação melhor". 0 Estado de São Paulo, p. 16, 2 ago. 2010a.

RAVITCH, D. The death and life of the great American School System: how testing and choice are undermining education. New York: Basic Books, 2010b.

RAVITCH, D. Vida e morte do grande sistema escolar americano: como os testes padronizados e o modelo de mercado ameaçam a educação. Porto Alegre: Ed. Sulina, 2011.

SÃO PAULO (Estado). Constituição Estadual de 05 de outubro de 1989. São Paulo: Assembleia Legislativa, 5 out. 1989.

SAVIANI, D. Educação não é filantropia. Presença Pedagógica, v. 3, n. 13, p. 5-15, jan./fev. 1997.

SAVIANI, D. Escola e democracia. 42. ed. Campinas: Autores Associados, 2012.

SAVIANI, D. PDE - Plano de Desenvolvimento da Educação: análise crítica da política do MEC. Campinas: Autores Associados, 2009.

Endereço para correspondência: Rua Bertrand Russell, 801, Barão Geraldo, Campinas, São Paulo, Brasil; dermeval.saviani.2013@gmail.com

Roteiro, Joaçaba, u. 45, p. 1-18, jan./dez. 2020 | e21512 |E-ISSN 2177-6059 